Васина Ольга Николаевна, Блинохватова Юлия Владимировна, Блинохватов Антон Александрович

\title{
ИСПОЛЬЗОВАНИЕ ИНТЕРАКТИВНЫХ ТЕХНОЛОГИЙ ОБУЧЕНИЯ В ПРОЦЕССЕ ЭКОЛОГИЧЕСКОЙ ПОДГОТОВКИ СТУДЕНТОВ
}

\begin{abstract}
Организация образовательного прочесса в условиях компетентностного подхода, предусмотренного Федеральным государственным образовательным стандартом высшего образования, требует от преподавателя пересмотра структуры, форм организачии деятельности, принципов взаимодействия субъектов прочесса обучении. Перспективными технологиями обучения становятся интерактивные технологии, объединяющие проблемное обучение, информационно-коммуникативные технологии, метод проектов. Использование диалогических методов общения, разнообразной творческой деятельности совместного поиска истины в прочессе экологической подготовки студентов способствует формированию эколого-ориентированного компонента компетенций.

Ключевые слова: компетентность, интерактивные технологии, экологическая подготовка, высиая икола, кейс-задания.

\section{Olga Vasina, Yuliya Blinokhvatova, Anton Blinokhvatov THE USE OF INTERACTIVE LEARNING TECHNOLOGIES IN THE PROCESS OF ECOLOGICAL TRAINING OF STUDENTS}

The organization of the educational process in terms of competence-based approach provided by the Federal state standards of higher education requires the teacher to review the structure, forms of organization of activities, principles of interaction of subjects of the learning process. Interactive technologies that combine problem learning, information and communication technologies, and project methods are becoming promising learning technologies.

The use of dialogical methods of communication, a variety of creative activities of joint search for the truth in the process of environmental training of students contributes to the formation of environmentaloriented component of competencies.
\end{abstract}

Key words: competence, interactive technologies, ecological training, higher school, case-tasks.

Bведение /Introduction. В условиях современной России достаточно остро стоит проблема подготовки компетентных специалистов, так как современное общество стремится к развитию творческого потенциала человека, его самостоятельности и конкурентоспособности на рынке труда. Это связано с научными и инновационными достижениями в большинстве отраслей народного хозяйства [9].

Актуализированный Федеральный государственный образовательный стандарт высшего образования (социальной ФГОС ВО) ориентирован на формирование профессиональной компетентности, предусмотренной профессиональными стандартами, раскрывающими цель профессиональной деятельности и трудовые функции: трудовые действия, необходимые умения и знания.

Основная цель профессиональной деятельности выпускников направления подготовки 36.03.01 Ветеринарно-санитарная экспертиза, в соответствии с профессиональным стандартом 13.012 Ветеринарный врач - сохранение здоровья животных и ветеринарной безопасности за счет профилактики и лечения всех видов животных и ветеринарно-санитарной экспертизы. Анализ функциональной карты данного вида профессиональной деятельности свидетельствует о важности 
экологической подготовки. При этом формирование системы экологических знаний, опыта эколого-ориентированных способов деятельности по охране животных, которые объединяются в позитивный опыт эмоционально-ценностного отношения (ЭЦО) к природе, особенность которого в его проекции на становление опыта ЭЦО к себе самому, обществу, здоровью, Отечеству определяют эколого-ориентированный компонент профессиональной компетентности [5]. Данные качества личности имеют определяющее значение в процессе профессионального самоопределения и социального становления и их формирование возможно при изучении дисциплины «Биология с основами экологии».

Доказано, что формированию системы знаний, кормления умений навыков, развитию критического мышления и опыта самостоятельной деятельности, сформированного на их основе, способствуют интерактивные приемы и методы [10]. Однако анализ литературы и практический опыт свидетельствуют об актуализации проблемы активного использования интерактивных технологий в организации учебного процесса, когда обучающиеся учатся четко формулировать, осознавать и высказывать свою позицию, что позволяет адаптировать их к реальным условиям [2, 4].

Использование интерактивных приемов и методов на практических занятиях по дисциплине «Биология с основами экологии» мы объясняем следующими причинами:

- формирование профессиональной компетентности, на которую ориентировано современное образование, предусматривает владение культурой критического мышления, способность работать с различными источниками информации, умение анализировать и обобщать ее;

- выпускникам вузов необходимо обладать способностью находить грамотное и правильное решение в возникающих жизненных ситуациях;

- повышение мотивации к освоению дисциплины, обеспечивающее осознанное изучение и закрепление теоретических знаний и практических умений;

- $\quad$ кейсовые задания и проектные технологии оказывают положительное воздействие на профессионализацию студентов и способствуют подготовке к предстоящей профессиональной деятельности $[2,3,7]$.

Однако интерактивные методы и приемы очень редко применяют на занятиях, что можно объяснить отсутствием разработанных учебных тематических кейсов, методики работы с ними и критериев для определения сформированности заданной компетенции.

Mamериалы и методы/Materials and methods. Использование интерактивных технологий в процессе экологической подготовки студентов предполагает выявление их образовательного потенциала для использования при формировании профессиональной компетентности, а также рассмотрение методических аспектов их использования [8]. Интерактивный формат экологической подготовки способствует формированию профессиональной компетентности и ориентирован:

- на формирование умений выявлять профессиональную проблему в реальной эколого-ориентированной ситуации;

- формирование способности анализировать и комментировать проблемную профессиональную эколого-ориентированную ситуацию с учетом системы общественных норм и ценностей;

- развитие умений предлагать разнообразные пути решения профессиональной эколого-ориентированной проблемы и обосновывать наиболее эффективный из них.

Повысить качество экологической подготовки позволяет использование кейс-заданий, в которых сочетаются полученные знания и накопленный опыт (таблица 1). 
Образовательный потенциал кейс-заданий

\begin{tabular}{|c|c|c|}
\hline Тема & Название кейс-задания & Характеристика кейс-задания \\
\hline $\begin{array}{l}\text { Альтернативные } \\
\text { источники энергии }\end{array}$ & Биотопливо & $\begin{array}{l}\text { - описывает реальное событие и принятие возможных мер; } \\
\text { - формулирует задачу по оценке причин, механизмов, } \\
\text { значения и последствий принятьх мер по использо- } \\
\text { ванию источников энергии. }\end{array}$ \\
\hline $\begin{array}{l}\text { Современный } \\
\text { глобальный } \\
\text { экологический кризис. } \\
\text { Субъективные } \\
\text { и объективные } \\
\text { причины }\end{array}$ & Мобильная отрава & $\begin{array}{l}\text { - характеризует критическую, нетипичную ситуацию; } \\
\text { - предлагает пересмотреть первоначальные расчеты и } \\
\text { планы, требующие радикального вмешательства; } \\
\text { - рекомендует внести собственные предложения, выра- } \\
\text { ботать стратегию поведения общества и отдельного } \\
\text { человека. }\end{array}$ \\
\hline Эволюция биосферы & Оцените позицию & $\begin{array}{l}\text { - иллюстрирует стандартную ситуацию, часто повторя- } \\
\text { ющуюся при схожих обстоятельствах, имеющих одни } \\
\text { и те же источники; } \\
\text { - предлагает выбрать и обосновать положительные и } \\
\text { отрицательные характеристики данной ситуации. }\end{array}$ \\
\hline $\begin{array}{l}\text { Генетика - научная } \\
\text { основа } \\
\text { селекции }\end{array}$ & $\begin{array}{l}\text { Модифицированный } \\
\text { друг }\end{array}$ & $\begin{array}{l}\text { - демонстрирует закономерности или механизмы био- } \\
\text { логических процессов; } \\
\text { - предлагает выявить положительные и отрицательные } \\
\text { результаты деятельности общества в их отношении; } \\
\text { - предлагает рассмотреть эффективность использо- } \\
\text { вания предложенных методов и приемов работы в } \\
\text { заданных условиях. }\end{array}$ \\
\hline
\end{tabular}

Анализируя реальную эколого-ориентированную ситуацию и ее признаки, студенты находятся в условиях необходимости выявления проблемы, проведения диагностики, поиска вариантов и выбора оптимального решения. При этом должны быть просчитаны все возможные последствия и препятствия.

Использование кейс-заданий предусматривает поэтапную организацию образовательного процесса.

Первый этап - «включение» - введение в содержание занятия новой, профессионально ориентированной информации. На данном этапе осуществляется актуализация имеющихся знаний, с опорой на межпредметные связи и стимулирование интереса к получению новой информации. Профессиональная значимость задачи способствует постановке собственных, личных целей изучения темы.

Второй этап - индивидуальное изучение кейса. Работа обучающегося на этом этапе ориентирована на осмысление и понимание полученной информации. Идет анализ, оценка и систематизация нового материала. При этом новая информация встраивается в канву имеющихся знаний и опыта.

Третий этап - разработка вариантов индивидуальных решений. Студент должен задуматься о природе изучаемого объекта, при этом происходит закрепление/присвоение новых знаний, собственного аргументированного представления об изучаемом профессионально ориентированном материале, которое важно уметь публично представить, показать достоинства и возможные направления эффективного использования.

Четвертый этап - обсуждение вариантов индивидуальных решений в группе. На этом этапе обучаюшиеся имеют возможность найти пути решения проблемы, разработать единое групповое решение и выработать индивидуальную линию поведения $[2,10]$.

Отметим, что активность обучающихся (при групповой форме работы) зависит от их числа и порядка размещения за рабочим столом, оптимальным считается вариант расположения четырех или шести человек за общим столом напротив, чтобы все обучающиеся, имея собеседников, 
могли принимать активное участие в работе. При этом важно соблюдать добровольность, учитывая личные взаимоотношения обучающихся, их общие интересы. С целью смены лидеров в группах и для разрушения складывающихся стереотипов, снижающих творческий потенциал, состав групп целесообразно изменять.

Важным этапом организации работы с кейс-заданиями является подведение итогов. Для кейсов, разработанных на примере реально существующих эколого-ориентированных ситуаций, это материал о том, как профессионально были решены данные проблемы. Для «кабинетных» кейсов важно обосновать версию преподавателя и акцентировать внимание на том, что предложенные кейсы могут иметь и другие решения.

Результаты и обсуждение / Results and discussion. Формирование эколого-ориентированного компонента занятиям профессиональной знакомство компетентности предполагает:

- накопление системных экологических знаний у обучающихся;

- овладение эколого-ориентированными умениями и навыками по профилю подготовки;

- социально позитивные изменения в мировоззренческих установках и ценностных отношениях к природе $[1,10]$.

В период с 1 сентября 2017 года по февраль 2019 года в Пензенском государственном аграрном университете (ПГАУ) изучение дисциплины «Биология с основами экологии» велось с использованием кейс-заданий и проектов.

Разработанные и систематизированные табличный кейс-задания и проекты мы включали в канву практических занятий по дисциплине «Биология с основами экологии» со студентами 1 курса (экспериментальная группа 56 человек) технологического факультета, обучающихся по направлению подготовки 36.03.01 Ветеринарно-санитарная экспертиза (уровень бакалавриата) (приказ Минобрнауки России от 01 декабря 2016 г. № 1516). Работа в экспериментальной группе была организована в направлении доминирования техническим диалогических проценты методов общения, совместного (интерактивных преподаватель, обучающиеся) поиска истины, приоритета творческой деятельности.

В контрольной группе (64 надо человека) на практических занятиях интерактивные методы и приемы не применялись.

Анализ литературы и проведенное исследование позволили на основе сравнения и прирашения таких показателей, как характер и выраженность эмоциональной реакции, тип когнитивных проявлений, уровень развития прагматизма и уровень развития практического взаимодействия с природными объектами выделить следующие уровни сформированности эколого-ориентированного компонента профессиональной компетентности и определить их критерии [6].

Низкий уровень отличают:

- ограниченное количество знаний предмета «Биология с основами экологии»;

- неустойчивый характер ценностного отношения к природе, себе самому, здоровью, родному краю, профессии.

Средний уровень характеризуется:

- наличием базовых знаний предмета «Биология с основами экологии»;

- сформированной системой ценностных ориентаций, предполагающих верное понимание, честное поведение, справедливость и уважение применительно к природе, себе самому, родному краю, профессии.

Высокий уровень предполагает:

- наличие глубоких целостных знаний предмета «Биология с основами экологии»;

- развитую систему ценностных ориентаций по отношению к природе, к себе самому, здоровью, родному краю, профессии;

- честность, уважение, ответственность и справедливость как основные правила, связанные с поведением по отношению к природе, себе самому, здоровью, родному краю, профессии. 
Уровень сформированности (за полученные результаты присваивались баллы) профессиональной компетентности мы определяли на основании:

- результатов аттестации студентов контрольной и экспериментальной групп (0-5 баллов);

- интерпретации методики «Завершение предложений» (1-3 балла);

- у умении четко определить профессиональную проблему в конкретной ситуации, отделить ее от других проблем (1-3 балла);

- способности прокомментировать проблемную профессиональную ситуацию с позиции системы общественных норм и ценностей (1-3 балла);

- возможности предложить различные пути решения профессиональной проблемы и обосновать наиболее эффективный из них с позиции системы общественных норм и ценностей (1-3 балла).

Показатели определения уровня сформированности эколого-ориентированного компонента профессиональной компетентности:

- ниже порогового (эколого-ориентированный компонент профессиональной компетентности не сформирован) - от 0 до 3 баллов;

- низкий: от 3 до 7 современный баллов;

- средний: от 8 до 12 баллов;

- высокий: от 13 интерактивные баллов и выше.

Приводим данные сравнительного правильно анализа показателей сформированности эколого-ориентированного компонента профессиональной компетентности у студентов, обучающихся в разных педагогических условиях. Студентам контрольной и экспериментальной групп были предложены задания семестровой аттестации, одинаковые предложения методики «Завершение предложения» [5], одинаковые проблемные профессиональные ситуации (таблица 2, рис. 1).

Уровень сформированности эколого-ориентированного компонента

Таблииа 2 профессиональной компетентности

\begin{tabular}{|l|c|c|c|c|c|c|}
\hline \multicolumn{1}{|c|}{$\begin{array}{c}\text { Континент } \\
\text { студентов }\end{array}$} & \multicolumn{2}{|c|}{ Контрольная групша (64 человека) } & \multicolumn{3}{c|}{ Экспериментальная групша (56 человек) } \\
\hline Баллы & $3-7$ & $8-12$ & 13 и более & $3-7$ & $8-12$ & 13 и более \\
\hline Уровень & низкий & средний & высокий & низкий & средний & высокий \\
\hline $\begin{array}{l}\text { Количество } \\
\text { человек }\end{array}$ & 24 & 36 & 4 & 12 & 30 & 14 \\
\hline $\begin{array}{l}\text { Проценты } \\
(\%)\end{array}$ & 37,5 & 56 & 6,5 & 21 & 53 & 25 \\
\hline
\end{tabular}

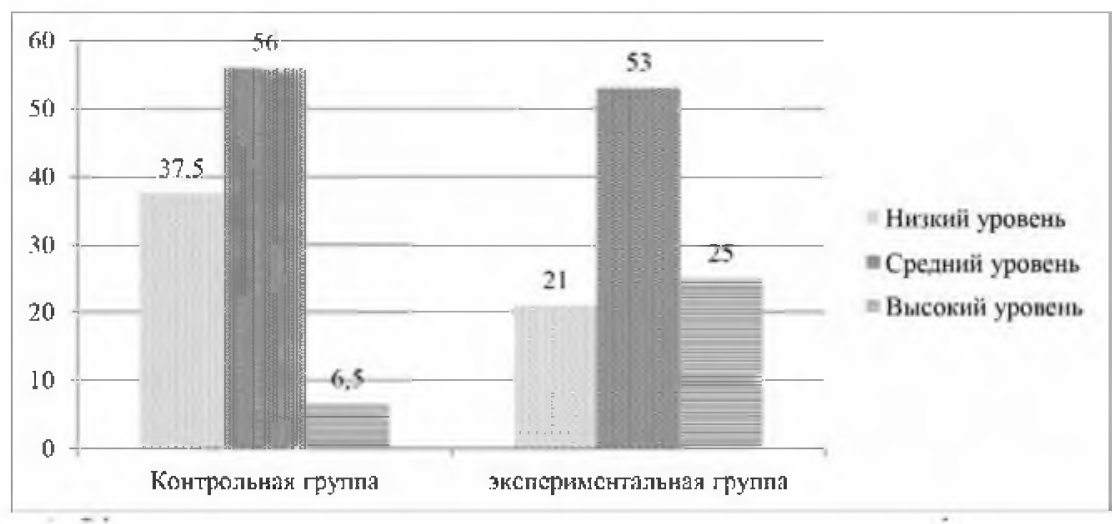

Рис. 1. Сформированность эколого-ориентированного компонента профессиональной компетентности 
Проведенное исследование свидетельствует о положительном влиянии использования интерактивных приемов и методов на формирование эколого-ориентированного компонента профессиональной компетентности у бакалавров направления подготовки «Ветеринарно-санитарная экспертиза».

Заключение/Conclusion. В ходе исследования были разработаны и применены некоторые виды интерактивных образовательных технологий, такие как метод кейсов и метод проектов с целью формирования эколого-ориентированного компонента компетентности у студентов.

При организации занятий с использованием проектной технологии и использованием метода кейс-стади может возникнуть ряд затруднений, поскольку студенты, привыкнув в к метод традиционным семинарам репродуктивного характера, неохотно переходят на новый вид деятельности. Но позитивные изменения были отмечены уже на третьем занятии:

- при подготовке к семинару у студентов появилась мотивация находить учебный материал по дополнительным источникам;

- на практических занятиях обсуждение стало более оживленным у студентов появилось желание активно учувствовать в образовательном процессе;

- к занятиям в экспериментальной группе чикагский постоянно были подготовлены 70-80\% студентов, в отличие от обеспечивающих другой контрольной группы (где стабильно были подготовлены к занятию 40-50\% алханов студентов).

Поэтому можно отметить, что применение интерактивных технологий заметно повышает эффективность обучения, формируя профессиональную компетентность у студентов. Они не только осознают практическую сторону получаемых знаний, но и активно включаются в деятельность, получая тем самым возможность улучшить профессиональные навыки работы.

\section{ЛИТЕРАТУРА И ИНТЕРНЕТ-РЕСУРСЫ}

1. Блинохватова, Ю. В., Васина, О. Н., Блинохватов, А. А. Использование интерактивных методов при формировании профессиональных компетенций. Педагогические и психологические технологии в условиях модернизации образования / Ю. В. Блинохватова, О. Н. Васина, А. А. Блинохватов: сб. ст. Международной научно-практической конференции. Уфа : Изд-во ООО «Аэтерна», 2017. С. $29-34$.

2. Блинохватова, Ю. В., Васина, О. Н., Блинохватов, А. А. Методические аспекты реализации метода кейсов для студентов высшей школы на примере дисциплины «Биология» / Ю. В. Блинохватова, О. Н. Васина, А. А. Блинохватов // Инновационные подходы в современной науке : по материалам XX Междунар. науч.-практ. конф. № 8 (20). Москва : Интернаука, 2018. С. 35-39.

3. Блинохватова, Ю. В., Васина, О. Н., Блинохватов, А. А. Обоснование использования проектной технологии для студентов высшей школы в условиях компетентностного подхода в образовании / Ю. В. Блинохватова, О. Н. Васина, А. А. Блинохватов // Вопросы педагогики. - Москва : НИИЦ «Институт стратегических исследований», 2018. С. 40-43.

4. Блинохватова, Ю. В., Васина, О. Н., Маковеева, О. С. Организация проектной деятельности обучающихся (на примере учебной дисциплины «Биология») / Ю. В. Блинохватова, О. Н. Васина, О. С. Маковеева // «ХІХ международные научные чтения (памяти А. А. Ухтомского) : сб. ст. Международной научно-практической конференции. Москва, 2017. - С. 97-100.

5. Васина, О. Н. Формирование эмоционально-ценностного отношения к природе у учащихся общеобразовательной школы через традиции народной экологии / О. Н. Васина: автореф. дис. ... канд. пед. наук: 13. 00. 01. - Пенза, 2004. -23 с.

6. Васина, О. Н., Пономарёва, О. Н., Шурыгин, С. В. Диагностика результатов экологической подготовки студентов в высшем образовании: методика «Завершение предложений» / О. Н. Васина, О. Н. Пономарёва, С. В. Шурыгин // Современные проблемы науки и образования. - 2018. - № 4. URL: http://www.science-education.ru/ru/article/view?id=27782 (дата обращения: 15.05.2019).

7. Галкина, Е. А. Применение образовательных кейсов в области методики обучения биологии как способ формирования целостного системного научного мировоззрения аспирантов / Е. А. Галкина // Концепт : научно-методический электронный журнал. 2015. Т. 3. С. 6-10. - URL: http:// koncept. ru/2015/65252 (дата обращения: 15.05.2019). 
8. Долгова, В. И., Гольева, Г. Ю., Аркаева, М. Ю. Реализация компетентностного подхода в системе высшего профессионального образования / В. И. Долгова, Г. Ю. Гольева, М. Ю. Аркаева // Концепт : научно-методический электронный журнал. - 2015. - T. 31. - C. 6-10. - URL: http://e-koncept. ru/2015/95508 (дата обращения: 15.05.2019).

9. Евдокимова, О.В., Пономарёва, О. Н., Грачёв, И. И. Формирование общекультурных компетенций в военных образовательных организациях высшего образования Министерства обороны Российской Федерации : монография / О. В. Евдокимова, О. Н. Пономарёва, И. И. Грачёв; под общ. ред. О. Н. Пономарёвой. - Пенза : Изд-во ПГУ, 2015. - С. 155-189.

10. Пономарева, О. Н., Васина, О. Н. Интерактивный формат построения образовательного процесса в высшей школе / О. Н. Пономарева, О.Н.Васина // Казанский педагогический журнал. - 2018. - № 5 (130). - C. 91-95.

\section{REFERENCES AND INTERNET RESOURCES}

1. Blinokhvatova, Yu. V., Vasina, O. N., Blinokhvatov, A. A. Ispol'zovanie interaktivnykh metodov pri formirovanii professional'nykh kompetentsii (The use of interactive methods in the formation of professional competencies) / Yu. V. Blinokhvatova, O. N. Vasina, A. A. Blinokhvatov // Pedagogicheskie i psikhologicheskie tekhnologii v usloviyakh modernizatsii obrazovaniya : sb. st. Mezhdunarodnoi nauchnoprakticheskoi konferentsii. - Ufa : Izd-vo OOO «Aeterna», 2017. S. 29-34.

2. Blinokhvatova, Yu. V., Vasina, O. N., Blinokhvatov, A. A. Metodicheskie aspekty realizatsii metoda keisov dlya studentov vysshei shkoly na primere distsipliny «Biologiya» (Methodological aspects of the implementation of the method of cases for high school students on the example of the discipline «Biology»)/ Yu. V. Blinokhvatova, O. N. Vasina, A. A. Blinokhvatov // Innovatsionnye podkhody v sovremennoi nauke : po materialam XX Mezhdunarodnoi nauchno-prakticheskoi konferentsii. - № 8 (20). - Moskva : Internauka, 2018. - S. 35-39.

3. Blinokhvatova, Yu. V., Vasina, O. N., Blinokhvatov, A. A. Obosnovanie ispol'zovaniya proektnoi tekhnologii dlya studentov vysshei shkoly $\mathrm{v}$ usloviyakh kompetentnostnogo podkhoda $\mathrm{v}$ obrazovanii (Rationale for the use of project technology for high school students in terms of competence approach in education) / Yu. V. Blinokhvatova, O. N. Vasina, A. A. Blinokhvatov // Voprosy pedagogiki. - Moskva : NIIC «Institut strategicheskih issledovanij», 2018. - S. 40-43.

4. Blinokhvatova, Yu. V., Vasina, O. N., Makoveeva, O. S. Organizatsiya proektnoi deyatel'nosti obuchayushchikhsya (na primere uchebnoi distsipliny «Biologiya») (Organization of project activities of students (on the example of the discipline «Biology»)) /Yu. V. Blinokhvatova, O. N. Vasina, O. S. Makoveeva // «XIX Mezhdunarodnye nauchnye chteniya (pamyati A. A. Ukhtomskogo)»: sb. st. Mezhdunarodnoi nauchno-prakticheskoi konferentsii. - Moskva, 2017. - S. 97-100.

5. Vasina, O. N. Formirovanie emotsional'no-tsennostnogo otnosheniya $\mathrm{k}$ prirode u uchashchikhsya obshcheobrazovatel'noi shkoly cherez traditsii narodnoi ekologii (Formation of emotional and value attitude to nature in secondary school students through the traditions of folk ecology): avtoref. dis. ... kand. ped. nauk: 13. 00. 01 / O. N. Vasina. - Penza, 2004. - S. 8-19.

6. Vasina, O. N., Ponomareva, O. N., Shurygin, S. V. Diagnostika rezul'tatov ekologichesko podgotovki studentov v vysshem obrazovanii: metodika «Zaversheniepredlozhenii» (Diagnostics of the results of environmental training of students in higher education: methodology "Completion of proposals») / O. N. Vasina, O. N. Ponomareva, S. V. Shurygin // Sovremennye problem nauki i obrazovaniya. - 2018. № 4. - URL http:www.science-education.ru/ru/article/view?id=27782 (data obrashcheniya: 15.05.2019).

7. Galkina, E. A. Primenenie obrazovatel'nykh keisov v oblasti metodiki obucheniya biologii kak sposob formirovaniya tselostnogo sistemnogo nauchnogo mirovozzreniya aspirantov (Application of educational cases in the field of methodology of teaching biology as a way of forming a holistic system of scientific Outlook of graduate students) / E. A. Galkina // Kontsept : nauchno-metodicheskii elektronnyi zhurnal. 2015. - T. 3. - S. 6-10. - URL: http://koncept.ru/2015/65252 (data obrashcheniya: 15.05.2019).

8. Dolgova, V. I., Gol'eva, G. Yu., Arkaeva, M. Yu. Realizatsiya kompetentnostnogo podkhoda v sisteme vysshego professional'nogo obrazovaniya (Implementation of the competence approach in the system of higher professional education) / V. I. Dolgova, G. Yu. Gol'eva, M. Yu. Arkaeva // Kontsept : nauchnometodicheskii elektronnyi zhurnal. - 2015. - T. 31. - S. 6-10. - URL: http://e-koncept.ru/2015/95508 (data obrashcheniya: 15.05.2019). 
9. Evdokimova, O. V., Ponomareva, O. N., Grachev, I. I. Formirovanie obshchekul'turnykh kompetentsii v voennykh obrazovatel'nykh organizatsiyakh vysshego obrazovaniya Ministerstva oborony Rossiiskoi Federatsii (Formation of General cultural competences in military educational institutions of higher education of the Ministry of defense of the Russian Federation) : monografiya / O. V. Evdokimova, O. N. Ponomareva, I. I. Grachev; pod obshch. red. O. N. Ponomarevoi. - Penza : Izd-vo PGU, 2015. - S. 155-189.

10. Ponomareva, O. N., Vasina, O. N. Interaktivnyi format postroeniya obrazovatel'nogo protsessa v vysshei shkole (Interactive format of the educational process in higher education) / O. N. Ponomareva, O. N. Vasina// Kazanskii pedagogicheskii zhurnal. - 2018. - № 5 (130). - S. 91-95.

\section{СВЕДЕНИЯ ОБ АВТОРАХ}

Васина Ольга Николаевна, кандидат педагогических наук, доцент кафедры общей биологии и биохимии, Федеральное государственное бюджетное образовательное учреждение высшего образования «Пензенский государственный университет». E-mail: onvasina $a$ yandex.ru

Блинохватова Юлия Владимировна, кандидат биологических наук, доцент кафедры почвоведения, агрохимии и химии, Федеральное государственное бюджетное образовательное учреждение высшего образования «Пензенский государственный аграрный университет». E-mail: julechka83 ainbox.ru

Блинохватов Антон Александрович, кандидат сельскохозяйственных наук, доцент кафедры пищевых производств, Федеральное государственное бюджетное образовательное учреждение высшего образования «Пензенский государственный технологический университет». E-mail: anton58@rambler.ru

\section{INFORMATION ABOUT AUTHORS}

Olga Vasina, Candidate of pedagogical sciences, Associate professor, sub-departmentof general biology and biochemistry, Penza State University. E-mail: onvasina@yandex.ru

Yuliya Blinokhvatova, Candidate of Biological sciences, Associate professor, sub-department «Soil science, agrochemistry and chemistry», Penza State Agrarian University. E-mail: julechka83@inbox.ru

Anton Blinokhvatov, Candidate of Agricultural sciences, Associate professor, sub-department «Food production», Penza State University of Technology. E-mail: anton58@rambler.ru 